Invited presentation for International Symposium on Mesoporous Molecular Sieves, Aug. 27-Sept. 2 2000, Québec, Qué, Canada.

\title{
Hierarchically structured functional porous silica and composite produced by evaporation-induced self-assembly
}

Hongyou Fan ${ }^{1,2}$, Scott Reed ${ }^{2}$, Tom Baer ${ }^{2}$, Randy Schunk ${ }^{2}$, Gabriel P. López ${ }^{1}$, and C. Jeffrey Brinker $^{1,2, *}$

${ }^{1}$ The University of New Mexico Center for Micro-Engineered Materials and Department of Chemical and Nuclear Engineering, Albuquerque, NM 87131.

${ }^{2}$ Sandia National Laboratories, Albuquerque, NM, 87185.

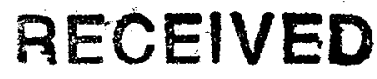

AUG 172080

\section{Abstract}

Recently so-called soft lithography approaches[1] have been combined with surfactant[2,3] and particulate[4] templating procedures to create oxides with multiple levels of structural order. But the materials thus formed have been limited primarily to oxides with no specific functionality, and the associated processing times have ranged from hours to days. Using self-assembling inks we have combined evaporation-induced (silica/surfactant) selfassembly (EISA)[5] with rapid prototyping techniques like micro-pen lithography (MPL)[6, 7], ink-jet printing (IJP) [8, 9], and dip-coating on micro-contact printed substrates to form hierarchically organized structures in seconds. By co-condensation of tetrafunctional silanes $\left(\mathrm{Si}(\mathrm{OR})_{4}\right)$ with tri-functional organosilanes $\left(\left(\mathrm{RO}_{3} \mathrm{SiR}^{\prime}\right)[10-12]\right.$ or bridged silsesquioxanes $(\mathrm{RO})_{3} \mathrm{Si}-\mathrm{R}^{\prime}-\mathrm{Si}(\mathrm{OR})_{3}$ ) or by inclusion of organic additives, we have selectively derivatized the silica framework with functional R' ligands or molecules. The rapid-prototyping procedures we describe are simple, employ readily available equipment, and provide a link between computeraided design and self-assembled functional nanostructures. We expect that the ability to form arbitrary functional designs on arbitrary surfaces will be of practical importance for directly writing sensor arrays and fluidic or photonic systems. 


\section{DISCLAIMER}

This report was prepared as an account of work sponsored by an agency of the United States Government. Neither the United States Government nor any agency thereof, nor any of their employees, make any warranty, express or implied, or assumes any legal liability or responsibility for the accuracy, completeness, or usefulness of any information, apparatus, product, or process disclosed, or represents that its use would not infringe privately owned rights. Reference herein to any specific commercial product, process, or service by trade name, trademark, manufacturer, or otherwise does not necessarily constitute or imply its endorsement, recommendation, or favoring by the United States Government or any agency thereof. The views and opinions of authors expressed herein do not necessarily state or reflect those of the United States Government or any agency thereof. 


\section{DISCLAIMER}

Portions of this document may be illegible in electronic image products. Images are produced from the best available original document. 
Key words: surfactant self-assembly, mesoporous, micro-pen writing, ink-jet printing, selective de-wetting,

Living systems exhibit form and function on multiple length scales and at multiple locations. In order to mimic such natural designs and impart life-like qualities to man-made materials, it is necessary to develop efficient strategies for assembling hierarchical materials. Conventional photolithography, although ubiquitous in the fabrication of microelectronics and MEMS, is impractical for defining features sizes below $0.1-\mu \mathrm{m}$ and poorly suited to pattern chemical functionality. Since the discovery of surfactant-templated silica mesophases ${ }^{[13]}$, considerable effort has been devoted to the development of molecular-scale, organic modification schemes to impart useful functionality to the pore surfaces[10, 12, 14-19]. Concurrently a variety of patterning strategies have been developed to define macroscopically the shapes of deposited thin-film mesophases and their locations on the substrate surface[2-4]. Our approach combines molecular-scale, evaporation-induced self-assembly (EISA)[5] of organically-modified mesophases[10,12,14-19] with macroscopic, evaporative, printing procedures. We report the rapid fabrication of hierarchical structures exhibiting form and function on multiple length scales and at multiple locations. At the molecular scale, functional organic moieties (Table 1) are positioned on pore surfaces; on the mesoscale, mono-sized pores are organized into one-, two-, or three-dimensional networks, providing size-selective accessibility from the gas or liquid phase; and on the macroscale, two-dimensional (2D) arrays and fluidic or photonic systems are defined. 


\section{Experimental}

Precursor solutions used as inks were prepared by addition of surfactants (cationic, CTAB; $\mathrm{CH}_{3}\left(\mathrm{CH}_{2}\right)_{15} \mathrm{~N}^{+}\left(\mathrm{CH}_{3}\right)_{3} \mathrm{Br}$ or non-ionic, Brij-56; $\mathrm{CH}_{3}\left(\mathrm{CH}_{2}\right)_{15}-\left(\mathrm{OCH}_{2} \mathrm{CH}_{2}\right)_{10}-\mathrm{OH}$ and Pluronic P123, $\left.\left.\mathrm{HO}\left(\mathrm{CH}_{2} \mathrm{CH}_{2} \mathrm{O}\right)_{20}\left(\mathrm{CH}\left(\mathrm{CH}_{3}\right) \mathrm{CH}_{2}\right) \mathrm{O}\right)_{70}-\left(\mathrm{CH}_{2} \mathrm{CH}_{2} \mathrm{O}\right)_{20}-\mathrm{H}\right)$, organosilanes (R'Si(OR) see Table 1), or organic molecules (see Table 1) to an acidic silica sol prepared from TEOS $\left[\mathrm{Si}\left(\mathrm{OCH}_{2} \mathrm{CH}_{3}\right)_{4}\right](\mathrm{A} 2 * *)$. The acid concentration employed in the $\mathrm{A} 2 * *$ synthesis procedure was chosen to minimize the siloxane condensation rate, thereby promoting facile self-assembly during printing[20]. In a typical preparation, TEOS, ethanol, water and dilute $\mathrm{HCl}$ (mole ratios: 1:3.8:1:5 $\times 10^{-5}$ ) were refluxed at $60^{\circ} \mathrm{C}$ for $90 \mathrm{~min}$. The sol was diluted with 2 volumes of ethanol followed by further addition of water and $\mathrm{HCl}$. Organosilanes ( $\mathrm{R}^{\prime}-\mathrm{Si}(\mathrm{OR})_{3}$, where $\mathrm{R}^{\prime}$ is a nonhydrolyzable organic functional ligand) were added followed by surfactants and (optionally) organic additives (see Table 1). Surfactants were added in requisite amounts to achieve initial surfactant concentrations $c_{0}$ ranging from 0.004 to $0.23 \mathrm{M}\left(c_{o}<c m c\right)$. The final reactant molar ratios were: 1 TEOS : $22 \mathrm{C}_{2} \mathrm{H}_{5} \mathrm{OH}: 5 \mathrm{H}_{2} \mathrm{O}: 0.093-0.31$ surfactant : $0.039-0.8$ organosilanes :

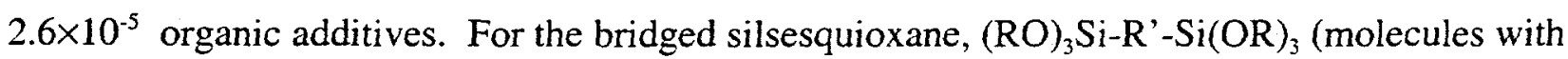
different R' are shown in scheme 1), the neat precursor was diluted in ethanol and mixed with 1 $8 \mathrm{wt} \% \mathrm{CTAB}$ or Brij-56 surfactant followed by addition of an aqueous solution of $\mathrm{HCl}$. The final reactant molar ratios were: $\mathrm{Si}: \mathrm{EtOH}: \mathrm{H}_{2} \mathrm{O}: \mathrm{HCl}$ :surfactant $=1: 22: 5: 0.004: 0.054-0.18$. Cohydrolysis of organosilanes with TEOS in the initial A2** sol preparation generally resulted in disordered worm-like mesostructures[21]. After pattern deposition and drying, the surfactant templates were selectively removed by calcination in a nitrogen atmosphere at a temperature sufficient to decompose the surfactant molecules $\left(-350{ }^{\circ} \mathrm{C}\right)$ without degrading the covalently bound organic ligands R' (confirmed by ${ }^{29} \mathrm{Si}$ MAS NMR spectroscopy) or by solvent extraction. 


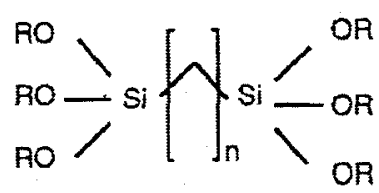

$(n=2,4,6,8,10)$

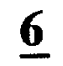

Scheme 1. Chemical formulae of bridged silsesauioxane monomers.

\section{Patterning Procedures}

1. Micropen lithography was performed using a Model 400a micropen instrument (Ohmcraft Inc., Pittsford, NY). The pen orifice was $50 \mu \mathrm{m}$ and the writing speed was $2.54 \mathrm{~cm} / \mathrm{s}$. The pattern was designed using AutoCAD software (AutoCAD release 14.01, Autodesk Inc., San Rafael, CA).

2. Ink jet printing was performed using a Model HP DeskJet $1200 \mathrm{C}$ printer (Hewlett-Packard Co., San Diego, CA). The pattern was designed using Microsoft PowerPoint 98 software.

3. Dip-coating of patterned (hydrophilic/hydrophobic) substrates was performed at a withdrawal speed of $7.6-51 \mathrm{~cm} \mathrm{~min}^{-1}$ under ambient laboratory conditions. Hydrophilic/hydrophobic patterns were created by microcontact printing $(\mu-\mathbf{C P})$ of hydrophobic, $n$ octadecyltrichlorosilane $\left(\mathrm{CH}_{3}\left(\mathrm{CH}_{2}\right)_{17} \mathrm{SiCl}_{3}\right)$ SAMs[22] on hydrophilic silicon substrates (hydroxylated native oxide) or by a technique involving electrochemical desorption of a hydroxyl-terminated SAM prepared from 11-mercaptoundecanol $\left(\mathrm{HO}\left(\mathrm{CH}_{2}\right)_{11} \mathrm{SH}\right)$ from patterned, electrically isolated gold electrodes followed by immersion in a $1 \mathrm{mM}$ ethanolic solution of 1 dodecanethiol, $\mathrm{CH}_{3}\left(\mathrm{CH}_{2}\right)_{11} \mathrm{SH}$ (ref. 29).

$\mu-C P$ of patterned surfaces Polydimethylsiloxane (PDMS) stamps that have relief structures consisting of circles, triangles, and stripes were fabricated according to published procedures[1]. 
The stamp was first inked with a $1 \mathrm{mM}$ solution of $\mathrm{HS}\left(\mathrm{CH}_{2}\right)_{11} \mathrm{CH}_{3}$ in ethanol and dried in a nitrogen stream. The stamp was then put in contact with the surface of the gold substrate for 30 seconds. Figure 1 illustrates the process of making the stamp and forming a patterned selfassembled monolayer on a gold surface, or silica surface, by $\boldsymbol{\mu}$-CP. The hydrophobic thiolderivatized sample was then washed with a $10 \mathrm{mM}$ solution of $\mathrm{HS}\left(\mathrm{CH}_{2}\right)_{11} \mathrm{OH}$ in ethanol to passivate the remaining area that had not contacted the stamp. Subsequently, the sample was rinsed with ethanol several times, then dried under a flow of nitrogen. For pattern fabrication on silicon wafers, a hydrophobic organosilane such as octadecyltrichlorosilane was used in hexane or toluene at a concentration of $10 \mathrm{mM}$. After first printing the hydrophobic silane the wafer was washed with hexane several times, dried in a nitrogen stream, and then placed in an $80^{\circ} \mathrm{C}$ oven to cure and promote siloxane condensation. In this case, the amorphous, hydroxylated silica surface itself serves as a hydrophilic pattern $\left(\mathrm{H}_{2} \mathrm{O}\right.$ contact angle less than $\left.10^{\circ}\right)$.

Patterned surfaces by an electrochemical method A wettable SAM was formed by immersing a $560 \AA$ gold film in $1 \mathrm{mM}$ ethanolic solution of 11 -mercaptoundecanol (HOC11SH). After one minute the SAM was dried under flowing nitrogen. Then a pulsed nitrogen-pumped dye laser emitting at $390 \mathrm{~nm}$ with a maximum intensity of $20 \mu \mathrm{J} /$ pulse (Laser Scissors from Cell Robotics, Albuquerque, NM) was focused on the gold surface through a microscope objective lens (Nikon Diaphot 300) to ablate the gold film and create interdigitized regions electrically isolated from one another.A reducing potential of $-2.4 \mathrm{~V}$ versus silver wire reference in $0.5 \mathrm{M}$ ethanolic potassium hydroxide was applied to desorb the 11-mercaptoundecanol (HOC11SH) from those regions in electrical contact with the electrodes. This left SAMs on regions electrically isolated from the reducing potential intact. Subsequent immersion of the sample in a $1 \mathrm{mM}$ ethanolic 
solution of hexadecanethiol $(\mathrm{C} 16 \mathrm{SH})$ created a sample with wettable (hydrophilic $-\mathrm{OH}$ terminated) and non-wettable (hydrophobic $-\mathrm{CH}_{3}$ terminated) regions.

\section{Results and Discussion}

Vital to rapid patterning procedures is the use of stable, homogenous inks that on evaporation undergo self-assembly to form the desired organically modified silica-surfactant mesophase. For this purpose we prepared oligomeric silica sols in ethanol/water solvents at a hydronium ion concentration $\left(\left[\mathrm{H}_{3} \mathrm{O}^{+}\right] \approx 0.01 \mathrm{M}\right)$ designed to minimize the siloxane condensation rate, thereby enabling facile silica-surfactant self-assembly during the brief time span of the writing operation (several seconds). Surfactants were added at an initial concentration $c_{o}$, much less than the critical micelle concentration, $c m c$, insuring homogeneity and longevity of the ink.

As a pattern of ink is metered onto a surface, preferential evaporation of ethanol causes enrichment of water, surfactant, and silicates, establishing a complex three-dimensional (3D; longitudinal and radial) gradient in their respective concentrations (see, for example, the 3D finite-element simulation of pen lithography in Fig.2b). Where the $\mathrm{cmc}$ is exceeded, cooperative silica-surfactant self-assembly creates micelles. Further evaporation, predominantly of water, promotes the continuous self-organization of micelles into silica-surfactant liquid-crystalline mesophases. Incipient liquid-crystalline domains are nucleated_at liquid-vapor interfaces[23] (at concentration $c<c m c$ ) and grow inward along compositional trajectories established by the steep, 3D evaporation-induced concentration gradient (Fig. 2).

The amphiphilic nature of some organosilanes like tridecafluoro-1,1,2,2tetrahydrooctyltriethoxysilane (TFTS; compound_1 in Table 1) causes them to behave as cosurfactants, positioning the hydrophilic $\operatorname{Si}(\mathrm{OR})_{x}(\mathrm{OH})_{3-x}$ headgroups in close proximity to the silica oligomers where they are incorporated into the framework upon further hydrolysis and 
condensation, thereby localizing covalently attached R' moieties on the pore surfaces. Using the general class of compounds referred to as bridged silsesquioxanes (RO) ${ }_{3} \mathrm{Si}-\mathrm{R}^{\prime}-\mathrm{Si}(\mathrm{OR})_{3}$ (Scheme 1), we report the formation of a new class of polysilsesquioxane mesophases with integral organic functionality. In contrast to hybrid mesophases where organic ligands or molecules are situated on pore surfaces[10-12, 14], this class of materials necessarily incorporates the organic constituents into the framework as molecularly dispersed bridging ligands. This new mesostructural organization is anticipated to result in synergistic properties derived from the molecular scale mixing of the inorganic and organic components. For example, the introduction of integral organic groups should impart toughness, hydrophobicity, and a reduced dielectric constant to the framework, while at the same time enhancing the thermal stability of the organic constituents. Such considerations are exceedingly important for current applications of silica mesophases like low dielectric constant (low $k$ ) coatings for the next generation of microelectronics, environmental sensors, and high temperature membranes. In order to establish structure-porosity relationships, we prepared a series of films from TEOS and $\underline{\mathbf{6}}(\mathrm{n}=2)$ with molar ratios TEOS: $\underline{6}=75: 25\left(\mathrm{~TB}_{1}\right), 50: 50\left(\mathrm{~TB}_{2}\right)$, and 25:75 $\left(\mathrm{TB}_{3}\right)$. Synthesis and processing procedures were chosen to create isotropic disordered (worm-like) thin film mesophases[18] with comparable film thicknesses (measured by spectroscopic ellipsometry) and porosities (measured by analyses of SAW-based $\mathrm{N}_{2}$ sorption isotherms). After calcination at $350^{\circ} \mathrm{C}$ under $\mathrm{N}_{2}$ to remove the surfactant templates, all films were vapor-treated with hexamethyldisilazane to avoid water adsorption. Table 2 compares values of the dielectric constants (measured using a standard capacitance-voltage technique employing a mercury probe), Young's modulus and hardness (modulus and hardness calculated from nanoindentation measurements at a constant indentation depth, assuming a Poisson's ratio of 0.2 ). We observe a consistent trend of 
increasing modulus and hardness and decreasing dielectric constant with substitution of the bridged silsesquioxane $\left(\equiv \mathrm{Si}-\left(\mathrm{CH}_{2}\right)_{2}-\mathrm{Si} \equiv\right)$ for siloxane $(\equiv \mathrm{Si}-\mathrm{O}-\mathrm{Si} \equiv)$ in the framework. This preliminary evidence suggests that introduction of integral organic groups into the frameworks of mesoporous materials can result in synergistic properties, promising an unprecedented ability to tune properties and function. The trend of increasing mechanical performance and decreasing dielectric constant observed here is of immediate and crucial interest to the burgeoning field of low $k$ dielectrics.

Hydrophobic but alcohol-soluble organic molecules like rhodamine-B partition into the hydrophobic micellar interiors upon ethanol evaporation[24], and ultimately become compartmentalized within the channel network of the resulting mesophase. Retention of the covalently attached functional organic moieties after surfactant removal by pyrolysis was confirmed using ${ }^{29} \mathrm{Si}$ magic-angle spinning (MAS) NMR spectroscopy. Fluorescence-imaging and ultraviolet-visible spectroscopy were used to confirm retention and functionality of optically active ligands and molecules.

Scheme 1 (Fig. 2) schematically illustrates direct writing of a mesoscopically ordered nanostructure, using micro-pen lithography, MPL[7]. Fig. 3a shows a macroscopic pattern formed in several seconds by MPL of a rhodamine-B-containing solution on a hydrophilic surface. The inset in Fig. 3a shows the corresponding fluorescence image of several adjacent stripes acquired through a $610-\mathrm{nm}$ bandpass filter, demonstrating retention of rhodamine-B functionality, and the transmission electron microscopy (TEM) image (Fig. 3b) reveals the ordered pore structure characteristic of a cubic thin-film mesophase. The MPL line width can vary from micrometers to millimeters. It depends on such factors as pen dimension[6], wetting characteristics, evaporation rate, capillary number $(C a=$ ink viscosity $\mathrm{x}$ substrate speed/surface 
tension) and ratio of the rates of ink supply and withdrawal (inlet velocity/substrate velocity). The effect of wetting has been demonstrated by performing MPL on substrates pre-patterned with hydrophobic, hydrophilic or mixed self-assembled monolayers (SAMs) Generally, line widths are reduced by increasing the contact angle and by reducing the pen orifice dimension and inlet/substrate velocity ratio.

The advantages of MPL are that we can use any desired combination of surfactant and functional silane as ink to print selectively different functionalities at different locations. Furthermore, we can use computer-aided design (CAD) to define arbitrary $2 \mathrm{D}$ patterns that can be written on arbitrary surfaces. For example, we have demonstrated writing rhodaminecontaining mesophases (refractive index $n=1.2-1.3$ ) on aerogel[25] and emulsion-templated thin films $(n=1.03-1.10)$, thereby directly defining optical wave-guide structures potentially useful for lasing[26].

MPL is best suited to write continuous patterns. Patterned macroscopic arrays of discrete mesostructures can be obtained readily by combining EISA with aerosol processing schemes like ink-jet printing, IJPP $[8,9]$. Figure $4 \mathrm{~b}$ shows an optical micrograph of an array of hydrophobic, mesoporous spots formed on a silicon substrate by IJP of a TFTS-modified ink. The IJP process dispenses the ink (prepared as for MPL) as monosized, spherical aerosol droplets. On striking the surface, the droplets adopt a new shape that balances surface and interfacial energies. Accompanying evaporation creates within each droplet a gradient in surfactant concentration that drives radially directed silica-surfactant self-assembly inward from the liquid-vapor interface[27]. The TEM micrograph (Fig. 4c) shows the ordered mesoporosity of a calcined, fluoroalkylated silica mesophase formed by IJJP. The link to computer-aided design, greater 
printing resolution achieved compared to standard ink (see Fig. 4a), and our ability to selectively functionalize the ink, suggest applications in sensor arrays and display technologies.

MPL and IJP are serial techniques. In situations where it is desirable to create an entire pattern with the same functionality, it might be preferable to employ a parallel technique in which the deposition process occurred simultaneously in multiple locations. Scheme 2 (Fig. 5) illustrates dip-coating on patterned SAMs. This rapid, parallel procedure uses microcontact printing[28] or electrochemical patterning[29] of hydroxyl- and methyl-terminated SAMs to define hydrophilic and hydrophobic patterns on the substrate surface. Then, using inks identical to those employed for MPL and IJP, preferential ethanol evaporation during dip-coating enriches the depositing film in water, causing selective de-wetting of the hydrophobic regions and ensuring self-assembly of silica-surfactant mesophases exclusively on the hydrophilic patterns. In this fashion, multiple lines, arrays of dots, or other arbitrary shapes can be printed in seconds. Recent density functional theory calculations[30] have established the ultimate resolution of this differential wetting technique to be $1-2 \mathrm{~nm}$.

Pattern formation on a hydrophilic/hydrophobic surface relies on the selective de-wetting of the hydrophilic coating precursor from the hydrophobic patterns. In order to demonstrate the de-wetting behavior on a stamped patterned surface, a patterned hydrophobic/hydrophilic gold substrate was immersed in a solution containing alcohol, water and propylene glycol. During dip-coating, preferential alcohol evaporation enriches the depositing film in water and propylene glycol, causing spontaneous de-wetting of the hydrophobic patterns. The scheme in Figure 6A shows the whole process of selective de-wetting of water and propylene glycol on a patterned gold surface. Figure $6 \mathrm{~B}$ shows an optical image of the plan-view of the resulting surface after dip-coating in a water/propylene glycol/ethanol solution. Although the initial solution wets both 
the hydrophilic and hydrophobic regions preferential evaporation of ethanol induces de-wetting of the hydrophobic regions causing the water/EG solution to reside exclusively on the hydrophilic regions. As shown, water only absorbs on hydrophilic region. In addition, de-wetting occurs not only on stripes but also on isolated circles. Here propylene glycol is used to suppress evaporation enabling us to image this de-wetting phenomenon.

Instead of using alcohol, water, and propylene glycol, an ink containing water, ethanol, silicate and surfactant prepared as described previously was used to prepare a patterned silica mesostructure. Figure 7 shows the corresponding patterned features including circles and stripes of different dimensions. The secondary ordering and length scale within the patterned macrostructure is tunable by using different sized surfactants (e.g, CTAB, Brij-56, and P123).

In addition to pure silica frameworks, the whole patterning process may be extended easily to create patterned functional organo silicate mesostructures. As an example, a fluorescent pattern was formed by adding rhodamine $\mathrm{B}$ to the dipping ink. Figure 8 shows an optical micrograph of fluorescence emission from a patterned, mesostructured silica film containing rhodamine- $\mathrm{B}$, confirming that the rhodamine $\mathrm{B}$ remains optically active in the mesostructured film. The TEM image in Figure 8 inset shows a uniform, ordered mesophase within the film.

As discussed above, scheme 2 (Fig. 5) illustrates the formation of a patterned propylamine-derivatized cubic mesophase by selective de-wetting followed by calcination to remove the surfactant templates (the organosilane used was aminopropyltrimethoxysilane- $\underline{\mathbf{3}}$ in Table 1). The TEM micrograph (Fig. 5, inset A) and $\mathrm{N}_{2}$-sorption isotherm (based on surface acoustic wave, SAW, measurements; Fig. 5, inset B) provide evidence of the mesostructural order and proof of the accessibility of the mesoporosity to the vapor phase. In order to make a pH-sensitive fluidic system, the covalently bound propyl-amine ligands were conjugated with a $\mathrm{pH}$-sensitive 
dye, 5,6-carboxyfluorescein, succinimidyl ester (5,6-FAM, SE) introduced in the pore-channel network of the cubic mesophase. After removal of any non-covalently-bonded dye, the uniform, continuous porosity of the amine-derivatized and dye-conjugated films was confirmed by TEM (Fig. 9c) and the corresponding SAW-based nitrogen sorption isotherm (Fig. 5, inset B). The slight reduction in film porosity after dye conjugation reflects the volume occupied by the attached dye moieties. The patterned, dye-conjugated array was used to monitor the $\mathrm{pH}$ of fluids introduced at terminal pads and transported by capillary flow into an imaging cell (scheme 2 , Fig. 4).

Figure 9a shows the fluorescence image of an array contacted with three different aqueous solutions prepared at $\mathrm{pH} 4.8,7.7$, and 12.0. Figure $9 \mathrm{~b}$ shows the corresponding emission spectra. Comparison with solution data (Fig. 9b) indicates that dye molecules covalently attached to the mesoporous framework retain similar functionality to those in solution. The combined fluorescence image (Fig. 9a) and plan-view and cross-sectional TEM micrographs (Figs 5 and $9 \mathrm{c}$ ) of the patterned dye-conjugated film demonstrate the uniformity of macro- and mesoscale features achievable by this evaporation-induced, de-wetting and selfassembly route. In comparison, films formed slowly (2-24 h) by nucleation and growth of thinfilm mesophases on patterned SAMs[2] were observed to have non-homogeneous, globular morphologies unsuitable for fluidic or photonic systems. We also note that in this case the mesoporous film formed on the hydrophobic regions.

\section{Conclusions}

We have combined evaporation-induced (silica/surfactant) self-assembly EISA with rapid prototyping techniques like pen lithography, ink-jet printing, and dip-coating on micro- 
contact printed substrates to form hierarchically organized structures in seconds. By cocondensation of tetrafunctional silanes $\left(\mathrm{Si}(\mathrm{OR})_{4}\right)$ with tri-functional organosilanes $\left((\mathrm{RO})_{3} \mathrm{SiR}^{\prime}\right)$ or by inclusion of organic additives, we have selectively derivatized the silica framework with functional R' ligands or molecules. In addition, the formation of a new class of hybrid polysilsesquioxane film mesophases with integral organic functionality, such as mechanical properties, has been demonstrated. The patterned materials exhibit form and function on multiple length scales: on the molecular scale, functional organic moieties are positioned on pore surfaces, on the mesoscale, mono-sized pores are organized into 1-, 2-, or 3-dimensional networks, providing size-selective accessibility from the gas or liquid phase, and on the macroscale, 2-dimensional arrays and fluidic or photonic systems may be defined. We believe that the evaporation-induced self-assembly process described here, and its elaboration in three different printing procedures, holds great promise for rapid prototyping of functional fluidic and photonic devices, along with displays and sensor arrays. Compared to alternative approaches like micromolding in capillaries (MIMIC), printing is considerably faster (seconds compared to 12 hours) and avoids the need for molds, masks, and resists. By using a spectrum of functional inks and interfacing with commercially available software, computer-aided design and rapid transcription of functional microsystems may soon be achievable.

\section{Acknowledgements}

We thank R. Assink for performing NMR experiments, P. Yang for technical assistance with micropen lithography. We thank D. Loy for providing bridged precursors and BASF for providing Pluronic P123. TEM investigations were performed in the Department of Earth and Planetary Sciences at the University of New Mexico. This work was supported by the US Department of Energy Basic Energy Sciences Program, the Sandia National Laboratories 
Laboratory-Directed Research and Development Program, the Defense Advanced Research

Projects Agency Bio-Weapons Defense Program, and the US Department of Defense Office of Naval Research. Sandia is a multiprogram laboratory operated by Sandia Corporation, a Lockheed-Martin Company, for the U.S. DOE under Contract DE-AC04-94AL85000.

\section{References}

[1] Y. Xia, G. M. Whitesides, Angew. Chem. Int. Ed. 1998, 37, 550.

[2] H. Yang, N. Coombs, G. A. Ozin, Adv. Mater. 1997, 9, 811.

[3] M. Trau, N. Uao, E. Lim, Y. Xia, G. M. Whitesides, I. A. Aksay, Nature 1997, 390, 674.

[4] P. Yang, T. Deng, D. Zhao, P. Feng, D. Pine, B. F. Chmelka, G. M. Whitesides, G. D. Stucky, Science 1998, 282, 2244.

[5] c. J. Brinker, Y. Lu, A. Sellinger, H. Fan, Adv. Mater. 1999, 11, 579.

[6] R. D. Piner, J. Zhu, F. Xu, S. Hong, C. A. Mirkin, Science 1999, 283, 661.

[7] P. Yang, D. Dimos, M. A. Rodriguez, R. F. Huang, S. Dai, D. Wilcox, Mat. Res. Soc. Symp. Proc. 1999, 542, 159.

[8] S.-C. Chang, J. Liu, J. Bharathan, Y. Yang, J. Onohara, J. Kido, Adv. Mater. 1999, 11, 734.

[9] D. Pede, G. Serra, D. De Rossi, Mat. Sci. and Eng. 1998, C5, 289.

[10] S. L. Burkett, S. D. Sims, S. Mann, Chem. Commun. 1996, 1367.

[11] C. E. Fowler, S. L. Burkett, S. Mann, Chem. Commun. 1997, 1769.

[12] M. H. Lim, C. F. Blanford, A. Stein, J. AM. Chem. Soc. 1997, 119, 4090.

[13] C. Kresge, M. Leonowicz, W. Roth, C. Vartuli, J. Beck, Nature 1992, 359, 710.

[14] C. E. Fowler, S. L. Burkett, S. Mann, Chem. Commun. 1996, 1367. 
[15] J. Liu, X. Feng, G. E. Fryxell, L.-Q. Wang, A. Y. Kim, M. Gong, Adv. Mater. 1998, 10, 161.

[16] B. Lebeau, C. E. Fowler, S. R. Hall, S. Mann, J. Mater. Chem. 1999, 9, 2279.

[17] S. Imagaki, S. Guan, Y. Fukushima, T. Ohsuna, O. Terasaki, J. Am. Chem. Soc. 1999, 121,9611 .

[18] B. J. Melde, B. T. Holland, C. F. Blanford, A. Stein, Chem. Mater. 1999, 11, 3302.

[19] T. Asefa, M. J. MacLachlan, N. Coombs, G. A. Ozin, Nature 1999, 402, 867.

[20] Y. Lu, R. Ganguli, C. A. Drewien, M. T. Anderson, C. J. Brinker, W. L. Gong, Y. X. Guo, H. Soyez, B. Dunn, M. H. Huang, J. I. Zink, Nature 1997, 389, 364.

[21] P. T. Tanev, T. J. Pinnavaia, Science 1995, 267, 865.

[22] C. D. Bain, E. B. Troughton, Y.-T. Tao, J. Evall, G. M. Whitesides, R. G. Nuzzo, J. Am. Chem. Soc. 1989, $111,321$.

[23] H. Yang, N. Coombs, I. Sokolov, G. A. Ozin, Nature 1996, 381, 589.

[24] A. Sellinger, P. N. Weiss, A. Nguyen, Y. Lu, R. A. Assink, W. Gong, C. J. Brinker, Nature 1998, 394, 256.

[25] S. S. Prakash, C. J. Brinker, A. J. Hurd, S. M. Rao, Nature 1995, 374, 439.

[26] P. Yang, G. Wirnsberger, H. C. Huang, S. R. Cordero, M. D. McGehee, B. Scott, T. Deng, G. M. Whitesides, B. F. Chmelka, S. K. Buratto, G. D. Stucky, Science 2000, 287, 465.

[27] Y. Lu, H. Fan, A. Stump, T. L. Ward, T. Reiker, C. J. Brinker, Nature 1999, 398, 223.

[28] J. L. Wilbur, A. Kumar, H. A. Biebuyck, E. Kim, G. M. Whitesides, Nanotechnology 1996, 7, 452.

[29] L. M. Tender, W. R.L., H. Fan, G. P. Lopez, Langmuir 1996, 12, 5515.

[30] L. J. Douglas Frink, A. G. Sallinger, J. Chem. Phys. 1999, 110, 5969. 
[31] R. A. Cairncross, P. R. Schunk, T. A. Baer, R. R. Rao, P. A. Sackinger, Int. J. Numer. Meth. Fluids to appear 2000.

[32] T. A. Baer, R. A. Cairncross, P. r. Schunk, R. R. Rao, P. A. Sackinger, Int. J. Numer. Meth. Fluids to appear 2000.

[33] G. C. Frye, A. J. Ricco, S. J. Martin, C. J. Brinker, in Better Ceramics Through Chemistry III, Vol. 121 (Eds.: C. J. Brinker, D. E. Clark, D. R. Ulrich), Mat. Res. Soc., Reno, Nevada, 1988, pp. 349.

\section{Figure captions}

Figure 1. Scheme of making of PDMS stamp and fabrication of patterns on gold and silica surfaces. (1) Micro-contact printing: formation of hydrophobic and hydrophilic regions. (2) Dipcoating of sol-gel precursors including silica, surfactant, water, and alcohol.

Figure 2. Scheme 1: micro-pen lithography (MPL) of a surfactant-templated mesophase. a, Simulation of 3D, binary fluid pattern dispensed on a flat substrate with the following parameters: pen orifice, $50.0 \mu \mathrm{m}$; substrate speed, $2.5 \mathrm{~cm} \mathrm{~s}^{-1}$; and fluid injection rate (inlet velocity), $4.0 \mathrm{~cm} \mathrm{~s}^{-1}$. Color contours represent evaporation-induced, 3D gradients in alcohol composition. Residence times for fluid elements entering at the pen orifice and exiting at section 3 ranged from $0.23-0.30-\mathrm{ms}$. Fluid was modeled as $54 \mathrm{vol} . \%$ ethanol and 46 vol. \% non-volatile phase with Reynolds number $\mathrm{Re}=1.25$ and $\mathrm{Ca}=0.000833$. An $a d$ hoc value of $45^{\circ}$ was chosen for the static contact angle. Note that this angle persists at all points on the dynamic contact line because of the dominance of surface tension at this low value of Ca. $\mathbf{b}$, The initially homogeneous sol metered on to the moving substrate experiences preferential evaporation of alcohol creating a complex 3D (longitudinal and radial) gradient in the concentrations of water 
and non-volatile surfactant and silicate species. Progressive enrichment of silica and surfactant induces micelle formation and subsequent growth of silica-surfactant mesophases inward from the liquid-vapor interface as recently demonstrated for aerosols ${ }^{[27]}$. The numerical method utilized for $\mathbf{a}$ and $\mathbf{b}$ consisted of a 3D finite-element discretization of the Navier-Stokes equations augmented with a 3D boundary-fitted mesh motion algorithm to track the free surface ${ }^{[31,32]}$. Special relations at the $3 \mathrm{D}$ dynamic wetting line were also applied.

Figure 3. Meandering patterned mesophase created by MPL. a, Optical micrograph of patterned rhodamine-B-containing silica mesophase deposited on an oxidized [100]-oriented silicon substrate at a speed of $2.54 \mathrm{~cm} \mathrm{~s}^{-1}$. Inset is a fluorescence image of rhodamine-B emission acquired through a $610-\mathrm{nm}$ bandpass filter, demonstrating retention of rhodamine-B functionality. $b$, Representative TEM micrograph of a fragment of the patterned rhodamine-Bcontaining film corresponding to a [110]-oriented cubic mesophase with lattice constant $a=10.3$ $\mathrm{nm}$. The sol was prepared by adding $0.01 \mathrm{wt} \%$ rhodamine-B to a silica/ $4 \mathrm{wt} \%$ Brij-56 sol. The

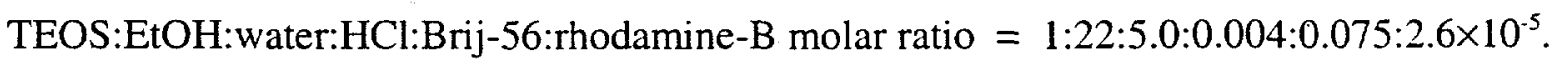

Figure 4. Patterned dot arrays created by ink-jet printing, IJP. a, Optical micrograph of a dot array created by IJP of standard ink (Hewlett-Packard Co.) on a non-adsorbent surface. b, Optical micrograph of an array of hydrophobic, mesoporous silica dots created by evaporationinduced silica-surfactant self-assembly during IJP on an oxidized [100]-oriented silicon substrate followed by calcination. $\mathbf{c}$, Representative TEM micrograph of a dot fragment prepared as in $\mathbf{b}$. The sol was prepared with molar ratio TEOS:TFTS:EtOH:water:HCl:Brij-56 = 1:0.05:22.0:5.0:0.004:0.075. The dot pattern used in $\mathbf{a}$ and $\mathbf{b}$ was designed using Microsoft PowerPoint 98 software. The printing rate was approximately 80 dots s$^{-1}$ and printer resolution 
300 dots per inch. The resolution achieved compared to standard ink and our ability to selectively functionalize the ink suggest applications in display technologies.

Figure 5. Scheme 2: Patterned functional mesostructure formed by selective de-wetting. Using microcontact printing or electrochemical desorption techniques, substrates are prepared with patterns of hydrophilic, hydroxyl-terminated SAMs and hydrophobic methyl-terminated SAMs. Preferential ethanol evaporation during dip-coating (1), causes water enrichment and selective de-wetting of the hydrophobic SAMs. Correspondingly film deposition occurs exclusively on the patterned hydrophilic SAMs. The sol was prepared by adding aminopropyltrimethoxysilane $\left(\mathrm{NH}_{2}\left(\mathrm{CH}_{2}\right)_{3} \mathrm{Si}\left(\mathrm{OCH}_{3}\right)_{3}\right.$, APS $)$ to a silica/4wt\% Brij-56 sol, resulting in a final molar ratio TEOS:APS:EtOH:water:HCl:Brij-56 = 1:0.8:22:5.0:0.011:0.075. Selective de-wetting followed by calcination results in a patterned, amine-functionalized, cubic mesoporous film as is evident from the plan-view TEM micrograph (inset A), showing a [100]-oriented cubic mesophase with $a=10.3 \mathrm{~nm}$ and nitrogen adsorption-desorption isotherm (inset $\mathrm{B}$, curve a) acquired for the thinfilm specimen using a surface acoustic wave ${ }^{[33 \mid}$ (SAW) technique. The dye conjugation reaction (2) was conducted by immersion in a $0.00002 \mathrm{mM}$ solution of 5,6-FAM, SE (Table 1) prepared in dimethylsulfoxide (DMSO) followed by exhaustive, successive washing in DMSO, ethanol, and water. The SAW-based nitrogen adsorption-desorption isotherm of the dye-conjugated mesoporous film is shown in inset B, curve b, confirming its pore accessibility. BET analyses of the sorption isotherms indicate that the dye conjugation reaction reduces the surface area from 750 to $545 \mathrm{~m}^{2} \mathrm{~g}^{-1}$ and the hydraulic radius from 2.2 to $2.1 \mathrm{~nm}$, but pore accessibility is completely retained as evident from combined TEM, SAW, and fluorescent-imaging results (Fig. 5a).

Figure 6. (A). A Dip-coating process of patterned surface in water/propylene glycol/ethanol solution. (B). The optical image of a plan-view of the resulting surface after dip-coating. 
Figure 7. SEM images of patterned mesoporous silica thin films in different features.

Figure 8. Fluorescence image of patterned mesostructured silica thin films containing rhodamine-B. Inset is the TEM image of corresponding film.

Figure 9. Patterned pH-sensitive fluidic system. a, Fluorescence image of three adjacent 5,6FAM, SE-conjugated pore channel networks after introduction of aqueous solutions prepared at $\mathrm{pH} 4.8,7.7$, or 12.0. Patterned dye-conjugated thin film mesophases were prepared according to Scheme 2 (Fig. 4). Aqueous solutions of varying $\mathrm{pH}$ were introduced on the terminal pads (Fig. 4) and transported into the imaging cell by capillary flow. Image was acquired using a Nikon Diaphot 300 inverted microscope and 520-nm bandpass filter. b, Fluorescence spectra of 5,6FAM, SE-conjugated mesoporous films upon exposure to aqueous solutions of $\mathrm{pH} 4.8,7.7$, and 12.0. Shown for comparison are fluorescence spectra of 0.1 _M solutions of 5,6-FAM, SE prepared in aqueous solutions of $\mathrm{pH} 4.8,7.7$, and 12.0. The similarity of the two sets of spectra confirms the maintenance of dye functionality upon conjugation within the mesoporous channel system. c, Cross-sectional TEM micrograph of the patterned, dye-conjugated thin-film mesophase, providing evidence of the 3D pore channel network. 


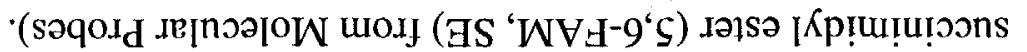

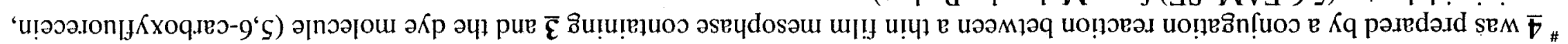

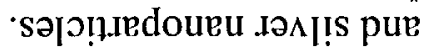

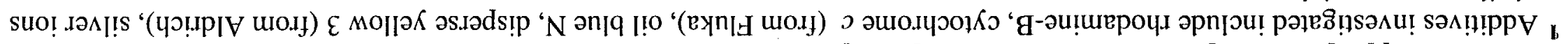

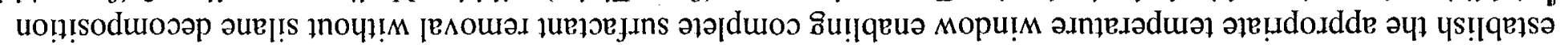

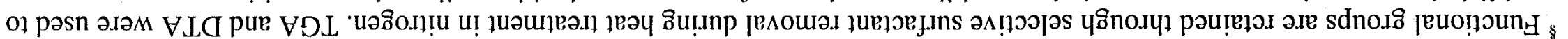

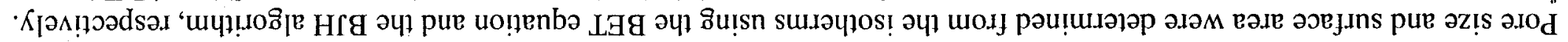

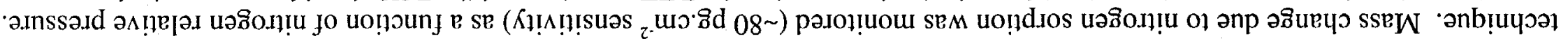

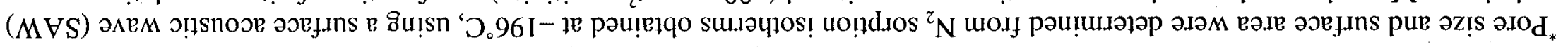

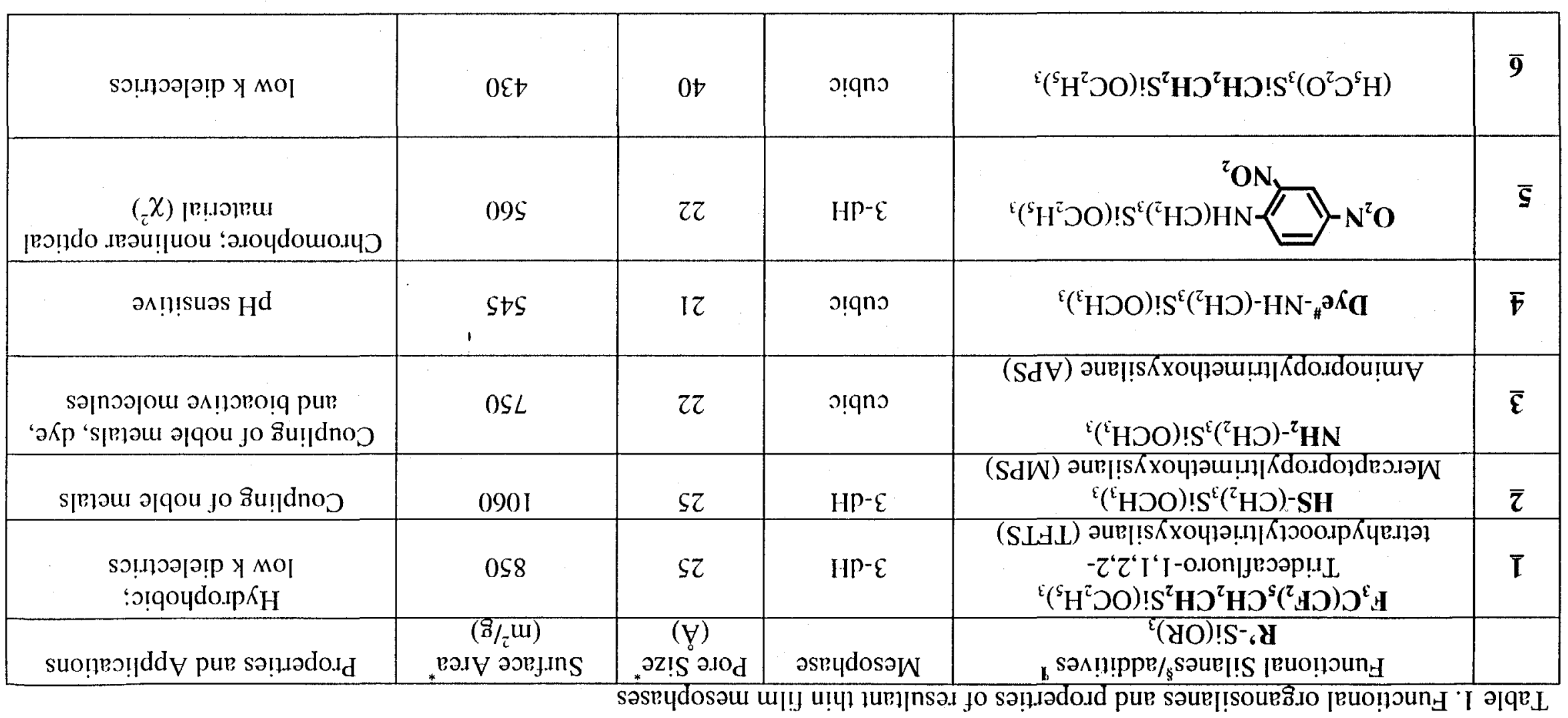


TABLE 2. Properties of Calcined TEOS $/ /\left(\equiv \mathrm{Si}-\left(\mathrm{CH}_{2}\right)_{2}-\mathrm{Si} \equiv\right)$ Mesoporous Thin films Prepared with 4 wt\% Brij-56 Surfactant

\begin{tabular}{|c|c|c|c|c|c|}
\hline $\begin{array}{c}\text { Framework } \\
\text { (TEOS:Silses } \\
\text { quioxane })\end{array}$ & $\begin{array}{c}\text { Thickness } \\
(\AA)\end{array}$ & $\begin{array}{c}\text { Dielectric } \\
\text { Constant }\end{array}$ & Porosity & $\begin{array}{c}\text { Modulus } \\
\text { (GPa) }\end{array}$ & $\begin{array}{c}\text { Hardness } \\
(\mathbf{G P a})\end{array}$ \\
\hline $\begin{array}{c}\mathrm{TB}_{1} \\
(75: 25)\end{array}$ & 3135 & 2.15 & $56 \%$ & 3.5 & 0.35 \\
\hline $\begin{array}{c}\mathrm{TB}_{2} \\
(50: 50)\end{array}$ & 3154 & 2.13 & $53 \%$ & 3.7 & 0.39 \\
\hline $\begin{array}{c}\mathrm{TB}_{3} \\
(25: 75)\end{array}$ & 3015 & 1.98 & $56 \%$ & 4.3 & 0.48 \\
\hline
\end{tabular}




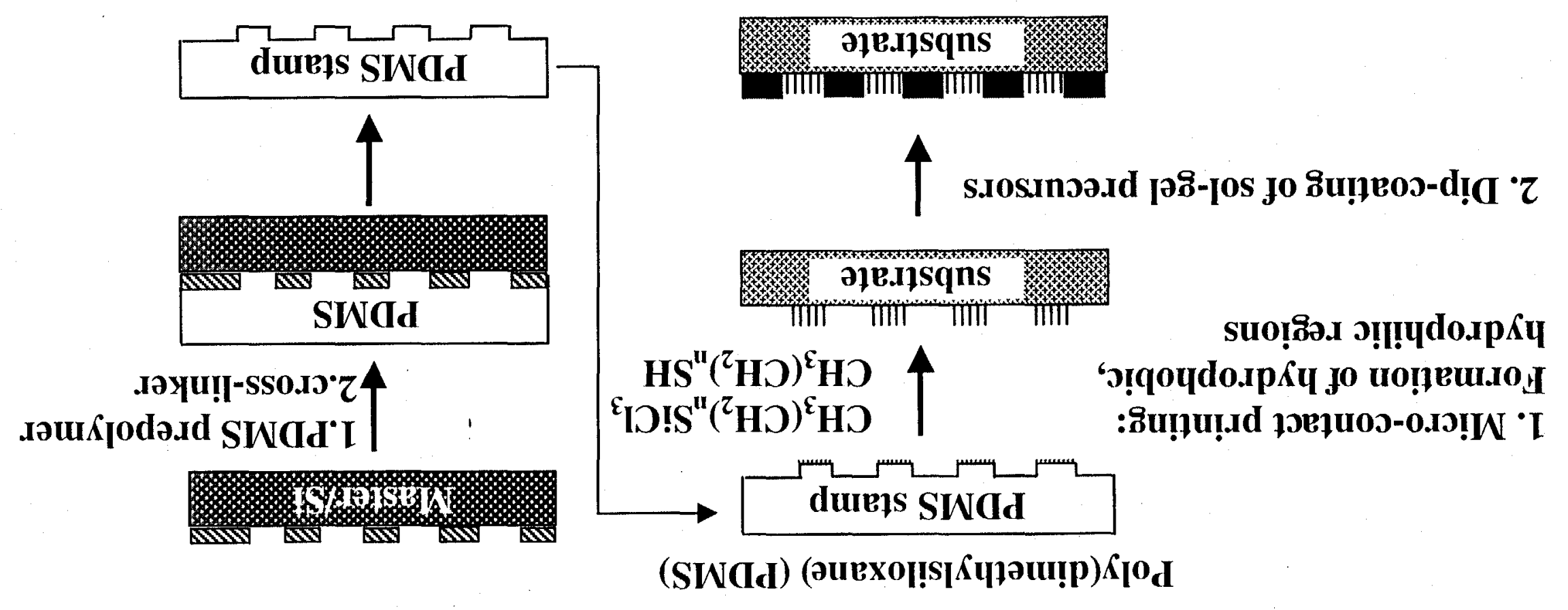




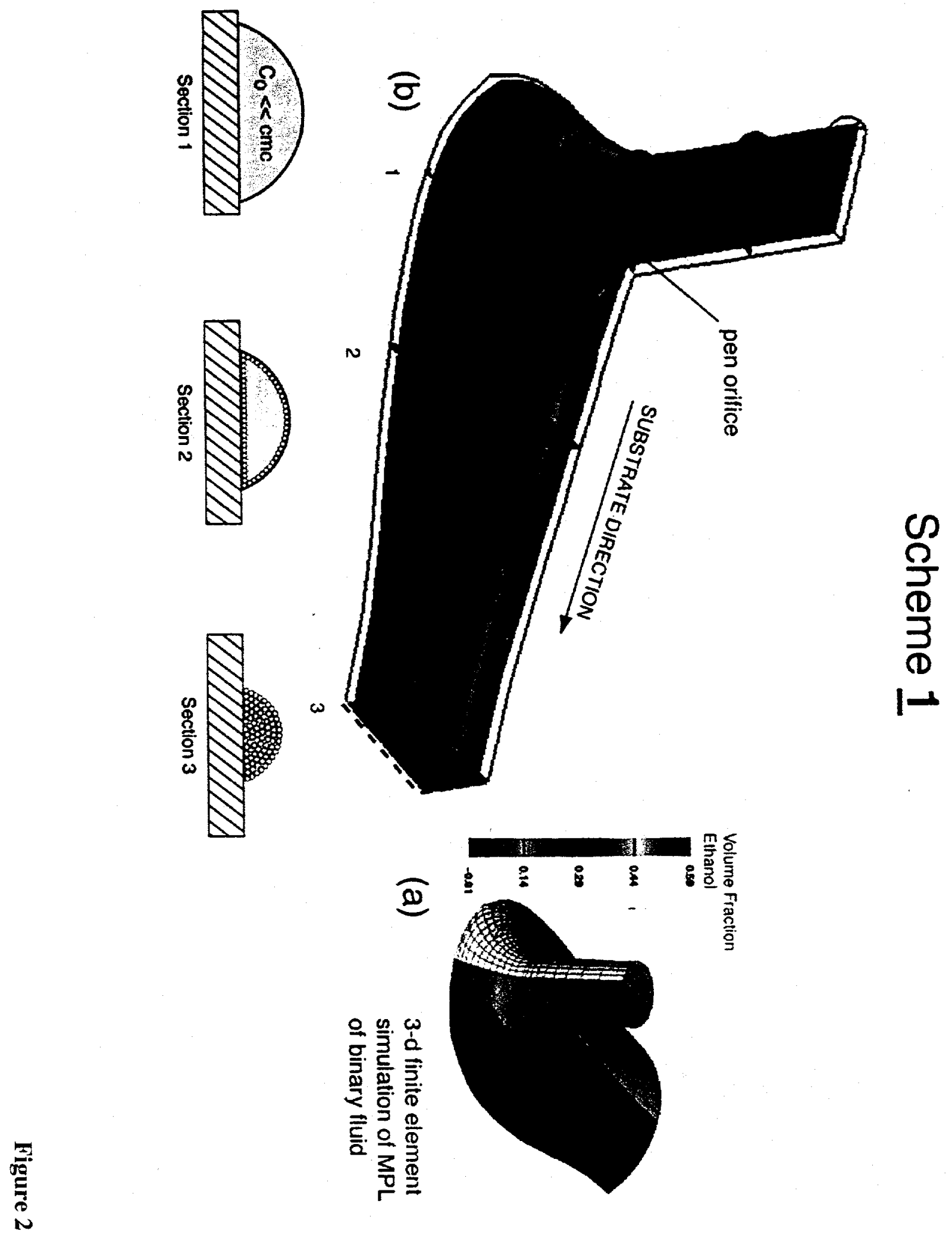



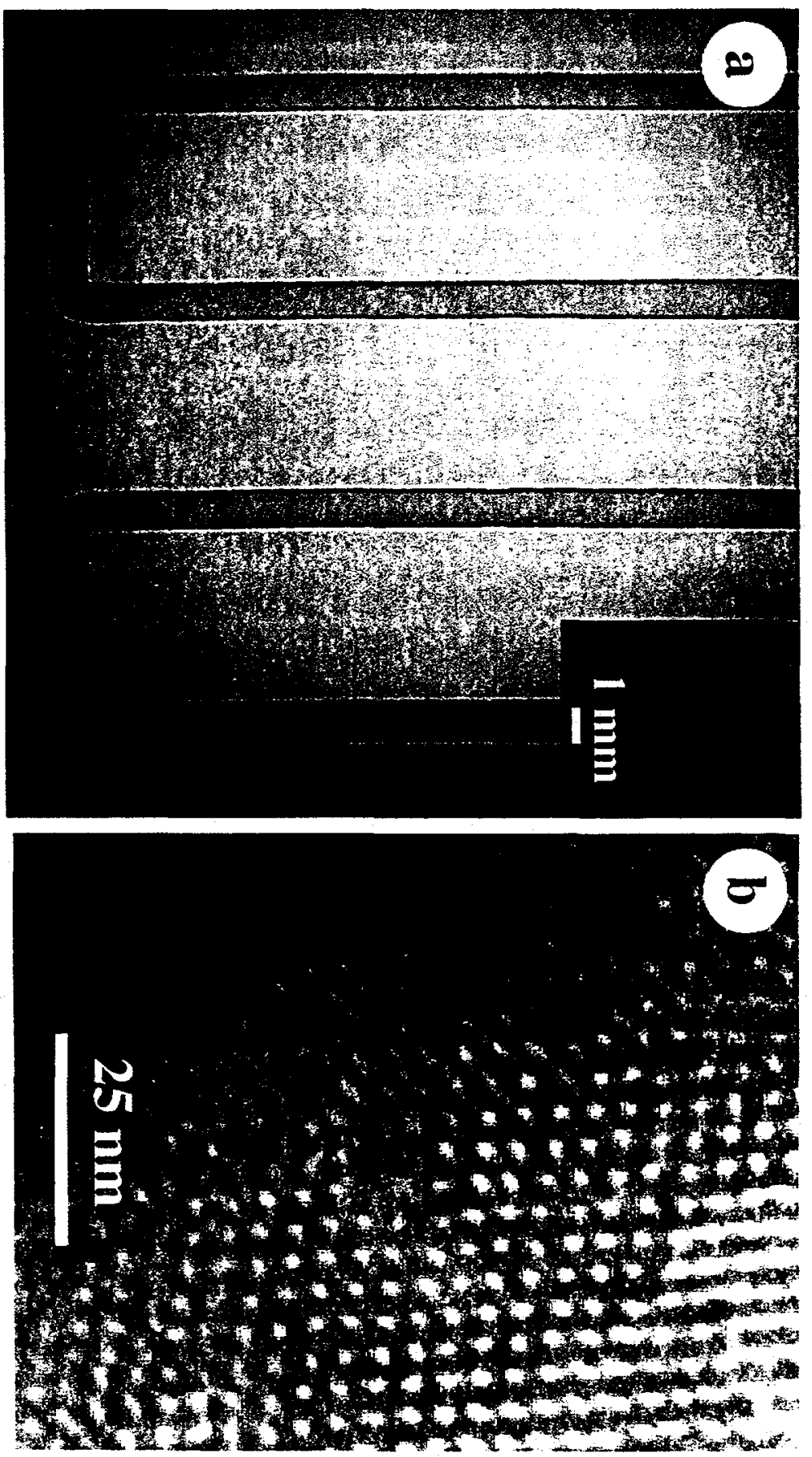

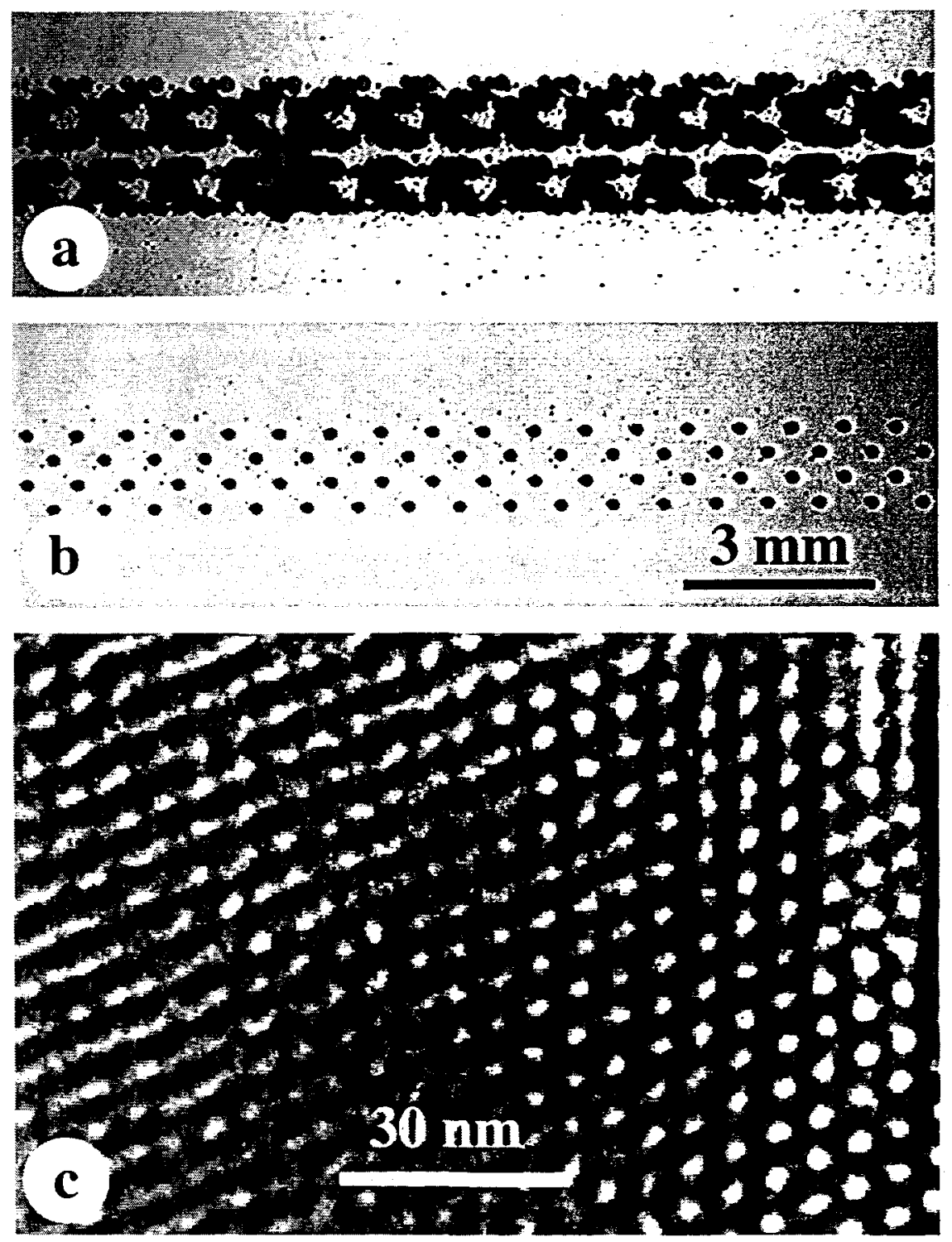

Figure 4 


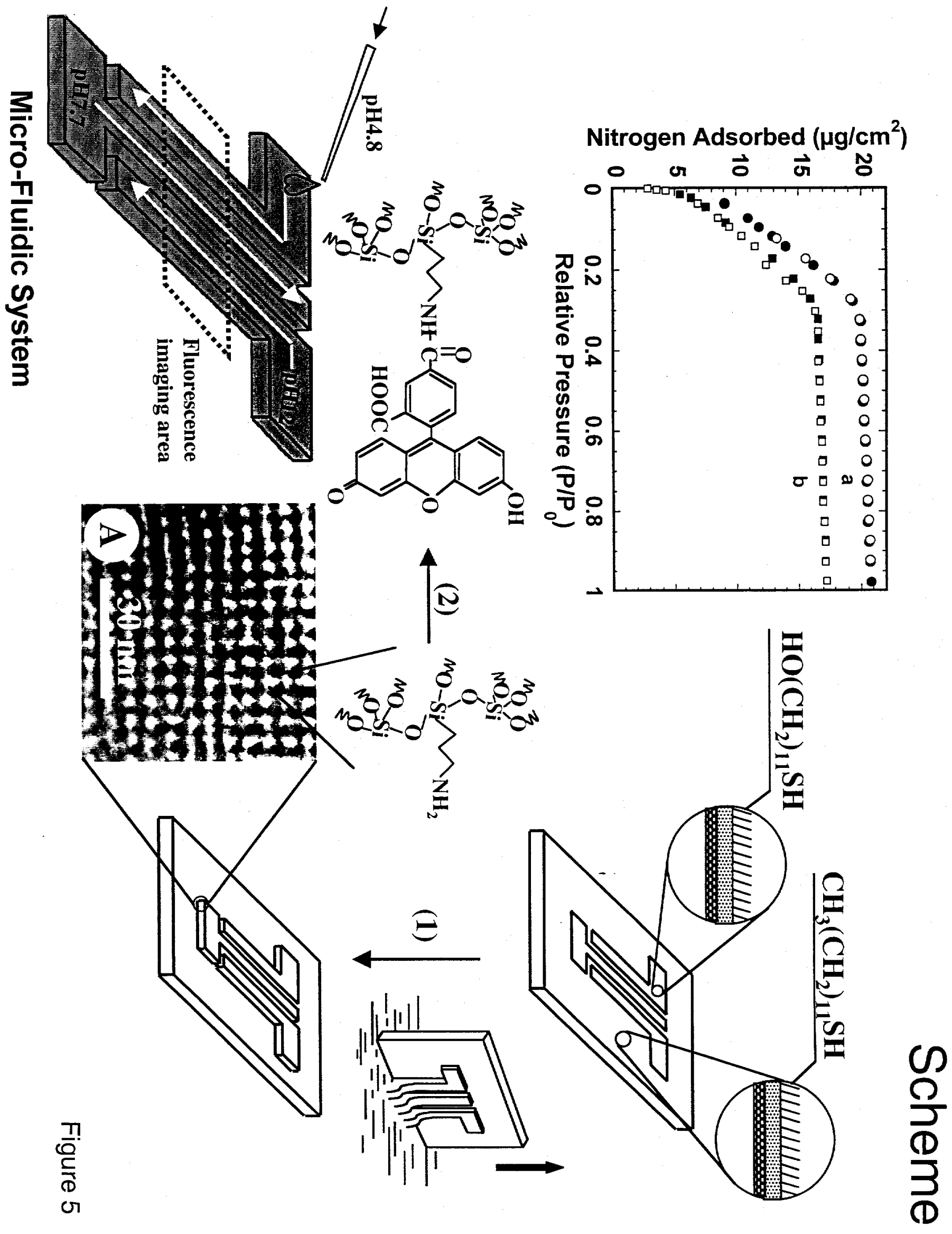



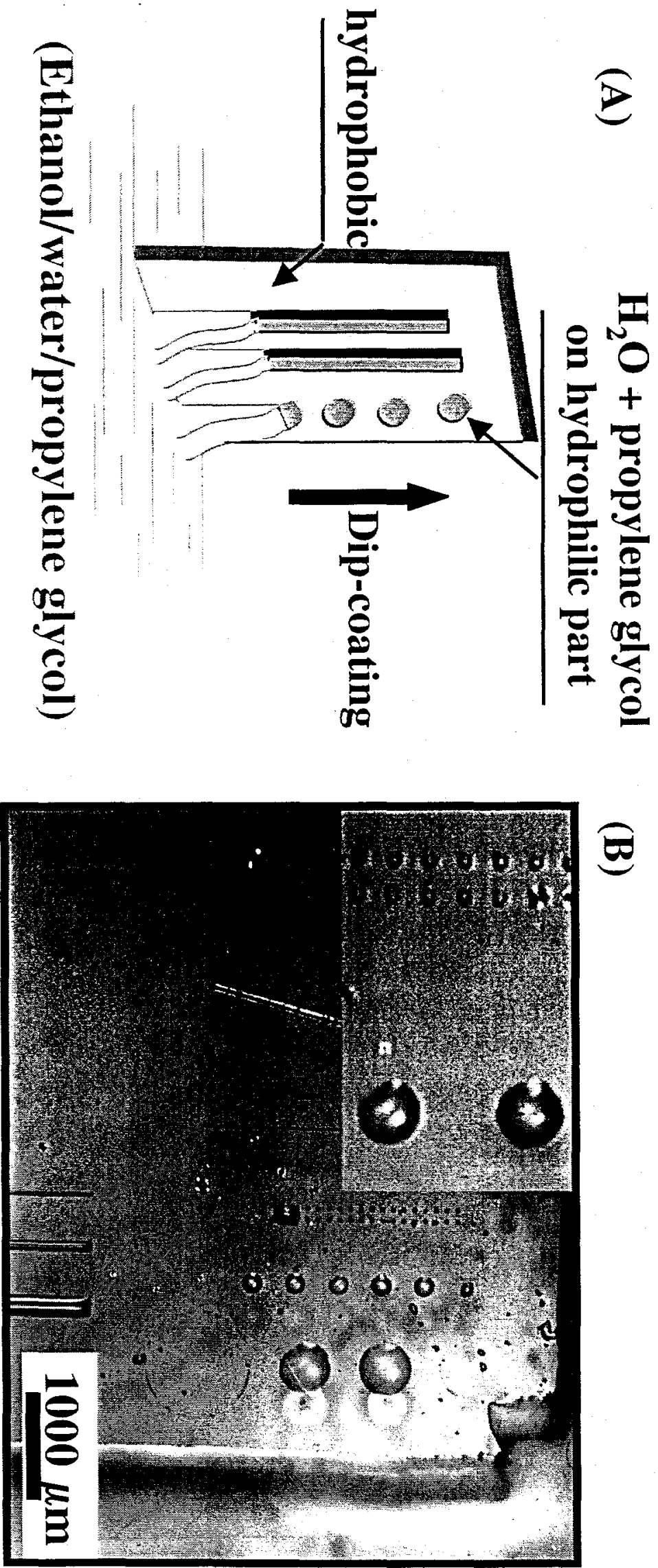

$\Xi$

录 


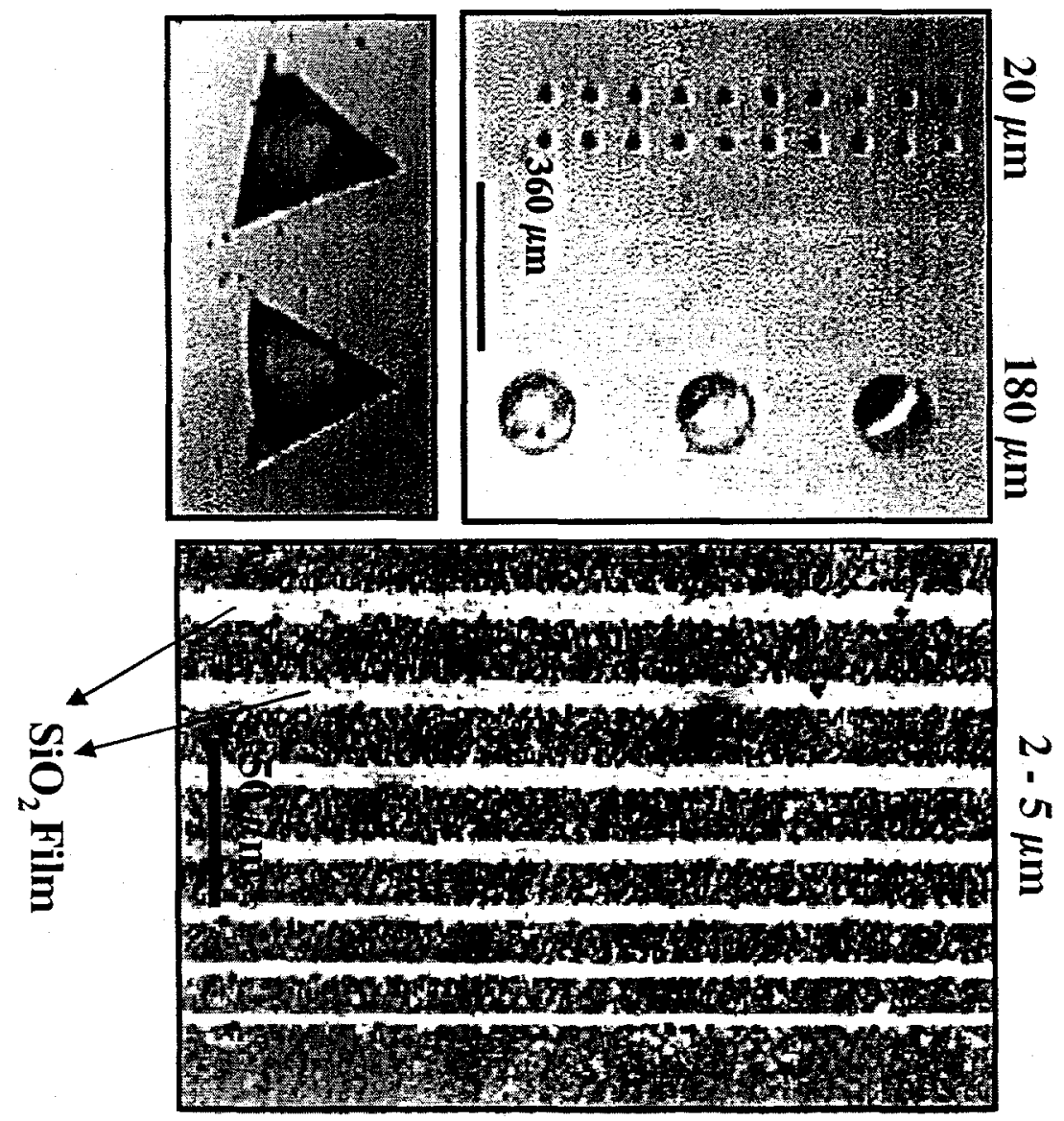

$\sqrt{0}$ 


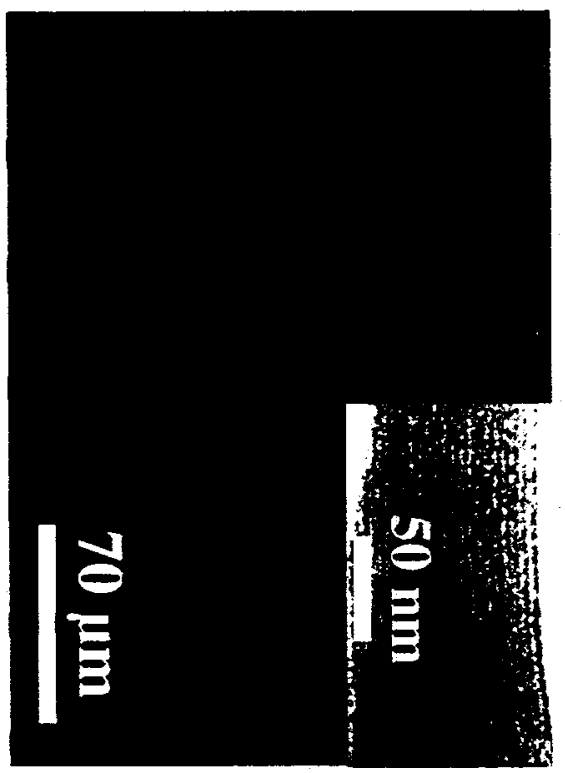

$\underset{\substack{3 \\ 0}}{\infty}$ 
6 əมก6!ป

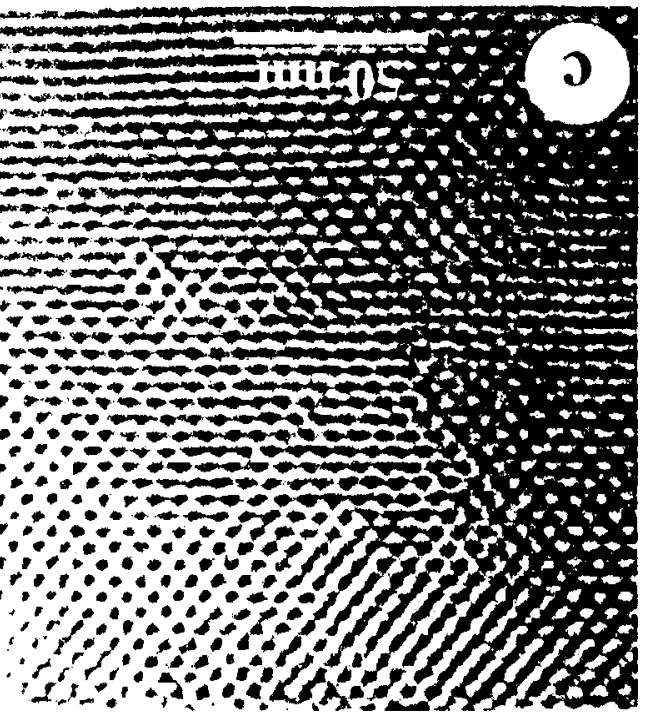

(uน) บ1าชับววАем

(9)
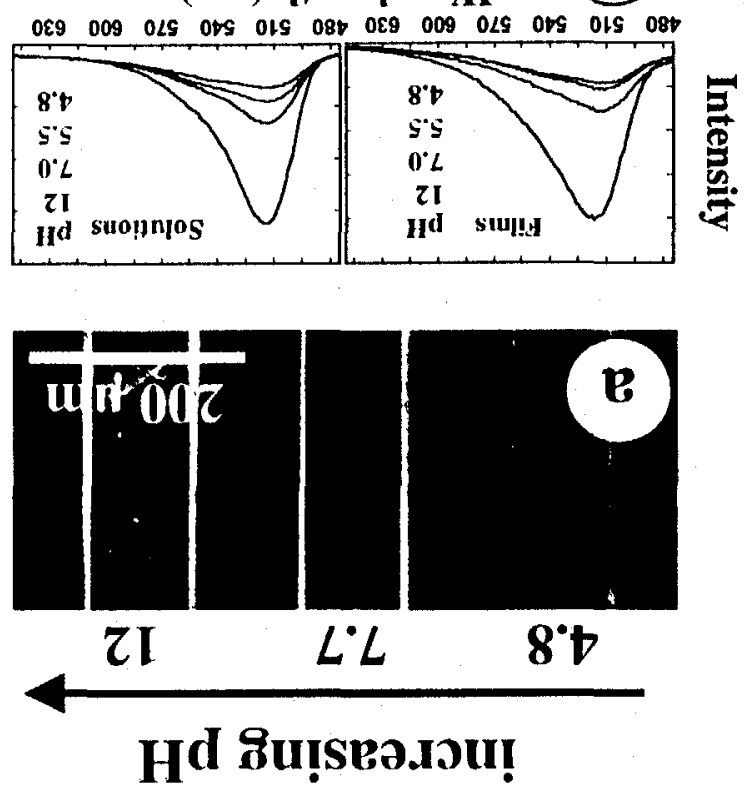